\title{
表示デバイスや視環境に依存しない物体の光沢感再現法
}

\section{Development of Device Independent Gloss Reproduction Model}

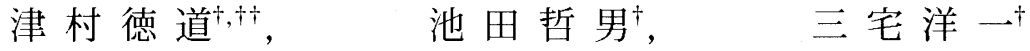

Norimichi Tsumura ${ }^{\dagger, \dagger}$, Tetsuo Ikeda ${ }^{\dagger}$ and Yoichi Miyake ${ }^{\dagger}$

\begin{abstract}
We proposed an empirical model to reproduce object gloss. This model was obtained by analyzing on observer rating experiment and surface reflectance characteristics of the object based on Phong's light reflection model. We showed that our model significantly reproduced gloss using display devices with different dynamic ranges. In modeling gloss, we introduced a method to estimate the relative radiance of the display by rating the gray chart experiment without any measurement devices. We also proposed a prototype that could be used as an online shopping system.
\end{abstract}

キーワード：質感解析，電子商取引, e-commerce, ヒューマンパーセプション, 反射モデル, コンピュータダラフィックス

\section{1.はじめに}

近年，インタネットの発達とブロードバンド化に伴い, 電 子商取引が急速に普及している. しかしディスプレイ上に 表示される商品画像は，その見えがディスプレイの特性や 視環境に大きく依存する. そのため装飾品などの, 色や光沢 感などの見えが重要視される商品では, 顧客満足度の低下 や返品率の増加により取引が困難な状態となっており，現 在活発に行われている取引の対象は書籍やC D などの見え が重要視されない商品に限定されている，そこで, 表示デ バイスや視環境に依存しない商品画像配信技術の開発が求 められている。

これまで表示デバイスに依存しない画像再現としては， $\mathrm{sRGB}^{8)}$ のように標準色空間を使用したり， ICC Profile ${ }^{9}$ の ようにデバイスのプロファイルを記述する手法が一般的で あった．しかしこれらの手法では，照明などの視環境が限 定されており, 各デバイスの特性を予め計測する必要があ るため実用的な手法ではない，また，表示デバイスに依存 しない色再現については考慮されているが, 色に次いで重 要とされる光沢感再現に関しては考慮されていない.

そこで本研究では，光沢感に着目し，表示デバイスや視 環境に依存しない光沢感再現方法を提案する. Ferwerda ${ }^{1)}$ らは物体の持つ物理的特性のうち, 色・偏角反射特性と人

\footnotetext{
2003 年 12 月 17 日受付, 2004 年 5 月 20 日最終受付, 2004 年 6 月 11 日採録 $\dagger$ 千葉大学大学院自然科学研究科

(广 263-8522 千葉市稲毛区弥生町 1-33, TEL 043-290-3262) †独立行政法人科学技術振興機構戦略的創造研究推進事業

(テ 332-0012 川口市本町 4-1-8 川口センタービル, TEL 048-226-5641)

$\dagger$ Graduate School of Science and Technology, Chiba University

(1-33, Yayoi-cho, Inage-ku, Chiba-shi, Chiba 263-8522, Japan)

$\dagger \dagger$ PRESTO, Japan Science and Technology Corporation (JST)

(Kawaguchi Center Building, 4-1-8, Honcho, Kawaguchi-shi, Saitama 332-0012, Japan)
}

間が知覚する光沢感の関係をモデル化した。本研究では, Ferwerda らの手法を拡張し，デバイスの最大輝度・物体の 偏角反射特性と人間が知覚する光沢感の関係をモデル化す ることにより，異なる最大輝度を持つデバイス間における 最大輝度に依存しない光沢感再現方法を実現した。また， ユーザによる表示デバイス上での簡単な操作により，その 最大輝度を推定する手法を提案する。これにより，放射輝 度計などの特別な測定装置を用いず，表示デバイスの最大 輝度を得ることができる，さらに輝度推定手法では，照明 などの視環境の影響による，相対的な表示デバイスにおけ る輝度の低下を考慮することができる，実験により，表示 デバイス・視環境に依存しない光沢感再現が実現されるこ とを確認した。

次節では，偏角反射特性を表現するための物体の反射モ デルについて概説する．３節では，2節で述べた反射モデル のパラメータ・表示デバイスの最大輝度・人間が感じる光 沢感の関係を主観評価実験によりモデル化する４４節では， ユーザによる表示デバイス上での簡単な操作により，デバ イスの最大輝度を推定する手法を提案し, その有効性を評 価する． 5 節では， 3 節の光沢感モデルと 4 節の輝度推定 手法の組合せにより，表示デバイスの見かけ上の最大輝度 を用いて，光沢感を有効に再現できることを示す． 6 節で は，実際にデバイス・視環境に依存しない商品画像配信シ ステムを構築する。7節で, まとめと議論を行う.

\section{2. 物体の反射モデル}

電子商取引において重要な要素の一つに商品画像が挙げ られる, 従来の商品画像は, 実際の商品を撮影した写真に よるものが主流であったが, 現在では自由に商品の拡大縮 小表示をし, 視点や照明条件を変化させることが可能な, 
ユーザの要求に応じたインタラクティブな閲覧が求められ ている，そのため近年では，コンピュータグラフィックス による商品画像表示が普及しつつある.

近年の商品開発では, 商品デザインの段階で $\mathrm{CAD}$ など の形式で商品のディジタルデータを持っており, コンピュー タグラフィックスによる商品画像を生成することは比較的 容易である．また，ディジタルデータがない場合も，偏角 分光イメージング法 ${ }^{12}$ などの手法を用いることで, 実際の 商品の形状情報と色を取得し，コンピュータグラフィック スによる商品画像を生成することが可能である，そこで本 研究では, 商品をコンピュータグラフィックスにより，イ ンタラクティブに閲覧することを想定する.

コンピュータグラフィックスにおいては，物体の任意の 質感・視点からの画像を合成するため, 物体に光が入射し た際の反射の様子をモデル化した反射モデルが用いられて いる. 反射モデルには，Shaferの2色性反射モデルかが一 般的に用いられる．2色性反射モデルでは，物体からの反 射光は表面反射成分と内部反射成分と呼ばれる二つの成分 から構成される.

図 1 に示すように，表面反射成分は物体と空気の屈折率 の違いにより, 物体表面で反射する光であり, 光源と同じ 色を持つ. 一方, 物体内部に入った光は, 色素粒子間で屈 折・吸収・散乱を繰り返す，入射光は波長に依存して色素粒 子に吸収されるため, 内部反射成分は物体固有の色を持つ.

2 色性反射モデルに基づく反射モデルとしては, Phong モ デル ${ }^{2)}$, Oren-Nayer モデル ${ }^{4)}$, Torrance-Sparrow モデル ${ }^{5)}$, Cook-Torrance モデルの, Ward モデル》などの様々なモデ ルが提案されている.この中で, Phong モデルは等方的な 反射面では正確な表現が可能である．また，比較的計算コ ストが低いため, リアルタイムレンダリングに適しており， OpenGL ${ }^{(0)}$ を始めコンピュータグラフィックスの様々な分野 で幅広く使われている. そのため本研究では, Phong モデ ルを用いた。

Phong モデルにおける反射光の強度分布を図 2 に示す. Phong モデルにおける反射光は, 表面反射成分では法線に 対して正反射し, 内部反射成分は等方的に反射する.この 2 成分の性質から, 光源角度 $\theta$ からの入射光を観測角度 $\theta^{\prime}$ から観測した際の画素值 $k(\theta)$ は式(1)のように定義される.

$$
\begin{aligned}
k(\theta) & =k_{s}(\theta)+k_{d}(\theta) \\
k_{s}(\theta) & =A_{s} \cos ^{n}\left(\theta-\theta^{\prime}\right) \\
k_{d}(\theta) & =A_{d} \cos (\theta)
\end{aligned}
$$

$k_{s}(\theta)$ は表面反射成分を表しており，表面反射成分の強度 $A_{s}$ とその広がり $n$ から構成される. $k_{d}(\theta)$ は内部反射成分を表 しており, 内部反射成分の強度 $A_{d}$ から構成される.

\section{3. 光沢感再現モデルの構築}

\section{1 主観評価実験}

知覚される光沢感がデバイスに依存する要因の一つとし

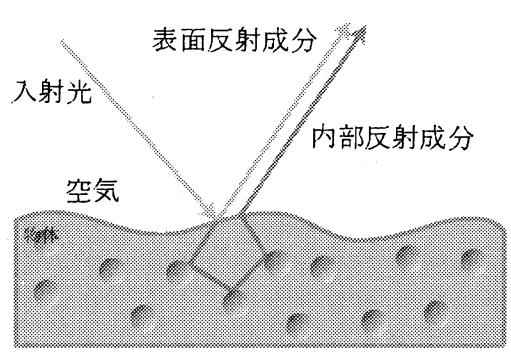

図 1 2色性反射モデル

Dichromatic reflection model.

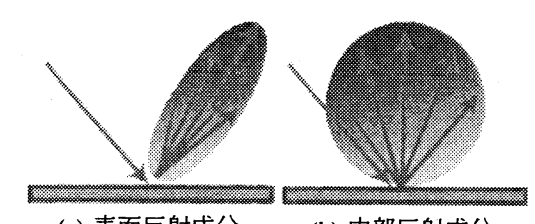

(a) 表面反射成分

(b) 内部反射成分

図 2 Phong モデルにおける反射光の強度分布 Reflected radiance distribution in Phong model.

て，デバイス間における輝度の違いが挙げられる，人間が 知覚する光沢感は, 表示デバイスの輝度に依存するため, 輝度の低いデバイスでは, 輝度の高いデバイスに比べて物 体の光沢感が小さく知覚される. 本研究では, デバイスの 輝度と光沢感の関係をモデル化し, 輝度に応じた光沢感再 現を行うことで, デバイスに依存しない光沢感再現を実現 した. 前節で述べたように, 物体の光沢感は Phong モデル の表面反射成分のパラメータである $A_{s}$ と $n$ に関係してい る.これら二つのパラメータとデバイスの輝度は物理量で あり, 光沢感は人間が感じる心理量である. 本研究では, 主 観評価実験によりこれらの物理量と心理量の関係を定量化 し, モデル式を構築した.

実験では，画面に様々な光沢感を持った実験画像が提示 される. 被験者は提示された画像に対して, 知覚した光沢 感を 0 から 100 までの数值で評価する. $A_{s}$ を $0.17,0.33$, $0.50,0.66,0.83,0.99$ の 6 通り, $n$ を $0.001,0.005,0.009$, $0.013,0.017,0.021$ の 6 通り, 輝度を 7 通り変化させた計 252 枚の実験画像を作成し，六人の被験者が各画像の光沢 感を評価した. この際, 表示デバイスの最大輝度が光沢感 に与える影響のみを議論するため, 実験に用いる物体の色・ 形状・材質などの特性は一定とし, 光沢感のみを変化させ た．また，実験は同一の表示デバイスを用いて行い，表示 デバイスのガンマ特性を保持させたまま, 最大輝度を変化 させた．図 3 は実験に使用した画像の一部である. (a) ( d) は横方向に $A_{s}$, 縦方向に $n$ が変化した異なる輝度の画像を 表している.

\section{2 実験結果}

主観評価実験の結果から得られたデータは，まず，個人 による評価尺度範囲の差異を考慮するため, 最大值と最小 值を用いて正規化した，正規化された評価值に対して，重 回帰分析を用いて処理することでモデル式を導出した．被 験者が知覚した光沢感 $G$ を従属変数とし, デバイスの輝度 


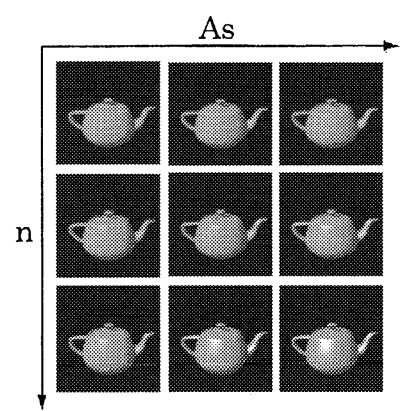

(a) $I=100$ のとき

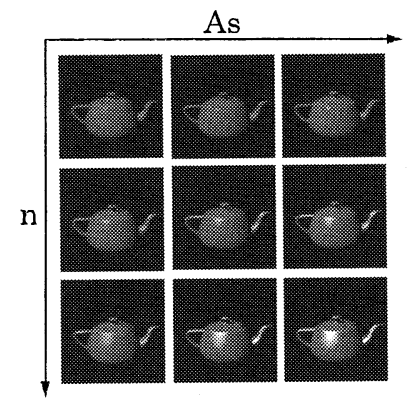

(c) $I=40$ のとき

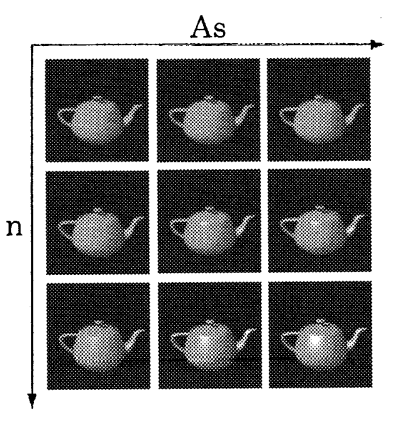

(b) $I=70$ のとき

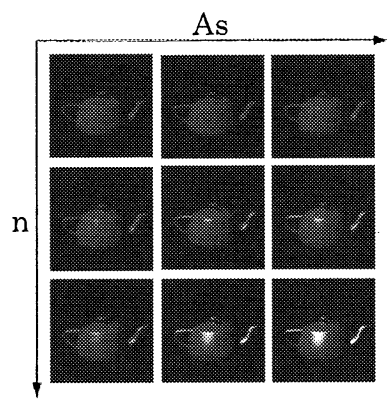

(d) $I=10$ のとき

図 3 輝度 $I$ を変化させた実験画像の一部

Synthesized images used in the experiment.

$I\left(c d / m^{2}\right)$ と表面反射成分のパラメータ $A_{s}, n$ を独立変数と して重回帰分析した結果, 式(2)のモデル式が得られた。

$$
\begin{array}{r}
G=54.7 \sqrt{A_{s}}+4.1 \times 10^{2} \sqrt{n}+5.4 \sqrt{I}-76.3 \\
\left(R^{2}=0.803\right)
\end{array}
$$

本モデル式では, $G$ が $A_{s}, n, I$ の関数となっているた め, 表示デバイスの輝度 $I$ の変化を, 表面反射成分のパラ メータ $A_{s}$ と $n$ を用いて補正することが可能である. 輝度 の低いデバイス上では $I$ は減少するが，その変化を $A_{s}$ と $n$ で補正して画像を生成することで, 光沢感 $G$ を一定にする ことが可能となった。

図 4 は式(2)において $G=50$ とした場合に, 光沢感が等 しく知覚される点を描画した等光沢感曲面である. 底面は $A_{s}$ と $n$ から構成され，縦軸は表示デバイスの輝度を表して いる. 等光沢感曲面上で表示デバイスの輝度に合わせて $A_{s}$ と $n$ を選択することで, 光沢感が等しく知覚される画像を 生成することが可能である.

図5 は, 図4において底面の $A_{s}$ と $n$ を $n=0.027 A_{s}+0.005$ として固定した場合の断面図である等光沢感曲線である. 図 中の曲線は $G=25,50,100$ とした場合に, 光沢感が等しく 知覚される画像を模式的に表している。 この等光沢感曲線 に沿って $A_{s}$ と $n$ を変化させた例を図 6 に示す。図 6(a) は 原画像を表しており, 図 6(b) は原画像を輝度の低いデバイ スで表示した画像である，紙面上では正確に表現できない が, 輝度の低いデバイスで表示したため, 原画像に比べて 光沢感が減少している傾向が確認できる. 図 6(c) は輝度の 低いデバイスで, 本モデル式を用いて, 光沢感を補正した 画像である. $A_{s}$ と $n$ を増加させることで輝度の減少が補正 され，原画像と同様な光沢感再現を実現している.

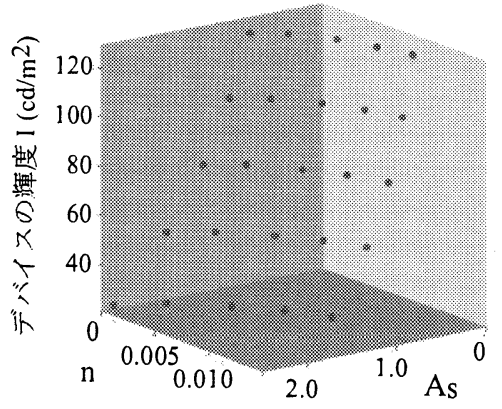

図 4 等光沢感曲面 Iso-gloss surface.

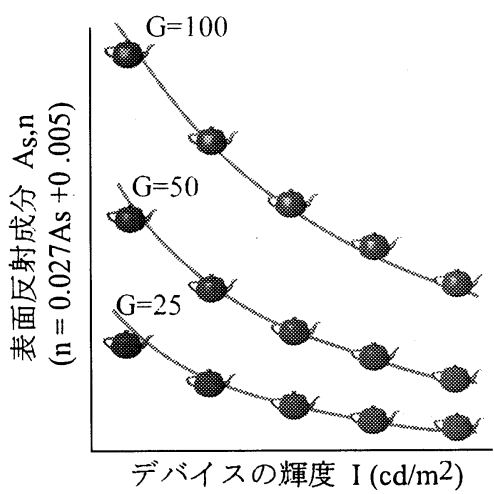

図 5 等光沢感曲線 Iso-gloss curves.

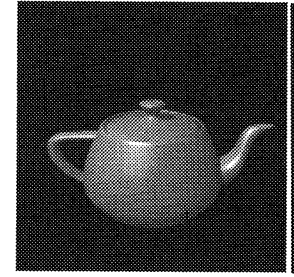

(a) 原画像

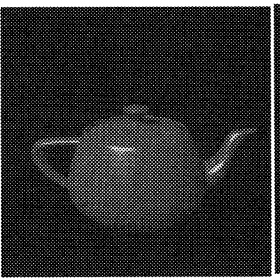

(b) 補正前 光沢感補正結果 Results of gloss correction.

表 1 光沢感補正モデルの有効性評価実験で使用したデバイスの種類 Devices used in the experiment.

\begin{tabular}{c|c}
\hline \hline デバイスの種類 & 輝度 \\
\hline $\mathrm{A}$ 社 L C D & $128.8 \mathrm{~cd} / \mathrm{m}^{2}$ \\
\hline $\mathrm{B}$ 社 C R T & $76.78 \mathrm{~cd} / \mathrm{m}^{2}$ \\
\hline $\mathrm{C}$ 社 携带電話 & $24.76 \mathrm{~cd} / \mathrm{m}^{2}$ \\
\hline
\end{tabular}

\section{3 モデル式評価実験}

本モデル式の有効性を評価するため, 主観評価実験を行っ た．実験に用いた表示デバイスを表 1 に示す．PC用のディ スプレイだけではなく, 携带電話の液晶画面を含めた輝度 の異なる 3 種類の表示デバイスを用いた.

実験では，本モデル式に基づいて求められた各表示デバ イスの輝度に適した画像を被験者に提示する。式(2)に打 ける光沢感 $G$ を $50,75,100$ の 3 通りとし、3 種類の表示デ バイスに対して，それぞれ画像を作成した，実験では，七 


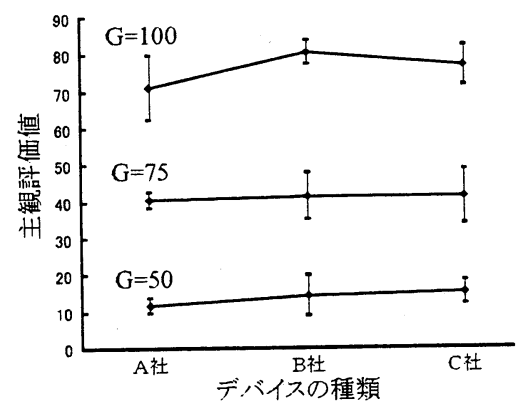

図 7 光沢感補正モデルの有効性評価実験結果 Results of subjective evaluation for gloss correction model.

人の被験者に対して，予め十数枚の画像を提示して評価方 法を習熟させた後, 各表示デバイスに 1 枚ずつ提示される 画像に対して光沢感を評価した。

図 7 に実験結果を示す. 横軸は表示デバイスの種類を表し ており, 左から表 1 の社製L C Dディスプレイ, B社製C R Tディスプレイ， C 社製携帯電話の液晶画面を表している. 図の縦軸は実験により得られた主観評価値であり, 被験者が 知覚した光沢感を表している. 各折れ線は $G=50,75,100$ における評価值と標準偏差を表している.

本モデルが光沢感を適切に補正できている場合は，デバ イス間の輝度の違いが, 補正され光沢感の差異が減少する ので, 各折れ線におけるデバイス間の主観評価值の差異が 小さくなると考えられる. 図7において, 縦軸の主観評価 值とモデル式の $G$ は異なるため, 縦軸の值より小さくなっ てはいるが， $G=50,75,100$ でのそれぞれの主観評価值の 差異はほとんどなく, 本モデルを用いることで, 光沢感を 適切に補正できることが確認できた. $G=100$ の場合は, $G=50,75$ の場合に比べて, 主観評価值の差異と標準偏差 が大きい．これは，実験に用いた画像の光沢感が比較的大 きく，階調推移の不足による光沢領域の擬似輪郭により，正 しく光沢感が評価されなかったことが原因であると考えら れる.

\section{4. 輝度推定モデルの構築}

\section{1 光沢感補正モデルの問題点}

前節では，表示デバイスに依存しない光沢感再現を目的 として, 光沢感補正モデルの構築を行い, またその有効性 を確認した. しかし，前節のモデル式を用いた光沢感の補 正には，表示デバイスの輝度 $I$ の情報が必要であった。

通常，表示デバイスの輝度を取得するには，放射輝度計 などの測定装置を用いるが, 実際の電子商取引では特別な 測定装置を用いることは，実用的ではない，また，照明環境 も知覚される光沢感を変化させる要因の一つであるが, 測 定には同様に特別な測定装置が必要である.

そこで本研究では, 測定装置の代わりにユーザの視覚を 利用した表示デバイスの輝度を推定する手法を提案する. ユーザの視覚を使用するため, 特別な測定装置を必要とせ

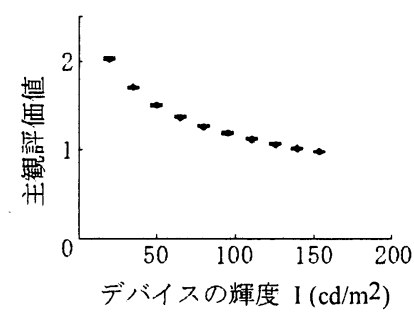

図 8 輝度推定モデル構築のための主観評価実験結果 Results of subjective experiments for radiance estimation model.

ず，任意の環境で高速に行うことが可能であるため，電子 商取引にも適している：また輝度だけではなく，照明環境 やユーザの個人差なども含めた総合的な情報を推定するこ とが可能である.

\section{2 主観評価実験}

黒い背景に白いパッチを提示して, パッチの色を次第に 白から灰色・黒と変化させていくと, パッチの色が完全な 黒になる前に，背景の黒とパッチの色が区別できなくなる. これはデバイスの輝度と関連性があり, 輝度の高いデバイ スでは背景と区別できる濃い灰色でも, 輝度の低いデバイ スでは区別がすることができない．

本研究ではこのことに着目し, パッチの色と背景の黒を 区別できる限界から，デバイスの見かけ上の最大輝度を推 定する手法を提案する．区別できる限界のパッチの画素值 と，デバイスの最大輝度の関係を定量化するため, 主観評 価実験を行った．実験では黒い背景に白いパッチを提示し， 五人の被験者は, パッチの色を次第に黒くしていく. 背景 の黒とパッチの色が区別できなくなる限界の画素值を取得 し, 輝度との関連性を定量化した. 実験は同一の表示デバ イスを用いて行い, ガンマ特性を保持したまま表示デバイ スの最大輝度を変化させることで様々な最大輝度を持つ表 示デバイスの代わりとした.

\section{3 実験結果}

図 8 に実験結果を示す．横軸が表示デバイスの最大輝度 を表し，縦軸は選択された画素值の最大輝度に対する割合 を表している. 各点は評価值と標準偏差を表しているが, 標 準偏差はほとんどなく，個人差が小さい結果が得られたこ とが確認できる，主観評価実験の結果から得られたデータ を, 重回帰分析しモデル式を導出した. デバイスの輝度 $I$ を従属変数とし，選択されたパッチの画素值 $V$ を独立変数 として重回帰分析した結果, 式(3)のモデル式が得られた.

$$
\begin{array}{r}
I=1.3 \times 10^{2}\left(\frac{V}{255}\right)^{2}-5.3 \times 10^{2}\left(\frac{V}{255}\right)+5.4 \times 10^{2} \\
\left(R^{2}=0.9934\right)
\end{array}
$$

本モデル式を用いることにより, 選択されたパッチから, 表示デバイスの見かけ上の最大輝度を推定することが可能 となる. 推定された輝度を式 (2)に代入することで, 光沢 
表 2 有効性評価実験で使用した照明環境の種類

Environmental illuminants used in the experiment.

\begin{tabular}{c|c|c}
\hline \hline 照明環境 & 色温度 & 照度 \\
\hline 暗室 & - & $0 l x$ \\
\hline 光源 1 & $3130 K$ & $1140 l x$ \\
\hline 光源 2 & $6550 K$ & $1800 l x$ \\
\hline
\end{tabular}

感補正に用いる表面反射成分のパラメータ $A_{s}, n$ を導出す ることが可能となった。

本手法は，従来から提案されているパッチの見え方に基づ いて，画面全体の明るさやコントラストなどのキャリブレー ションを行う Macintosh の Color Sync や Adobe の Adobe Gamma とは異なり, 物理モデルに基づいていることが特 徵である. そのため従来法と比較して, より定量的な光沢 感再現が可能である.

\section{5. 光沢感再現評価実験}

提案した光沢感モデルと輝度推定モデルは，暗室下での 主観評価実験に基づいて構築されたため, 蛍光灯などの光 源下での正確な光沢感再現については保障されていない，4 節において提案した暗室下で作成された輝度推定モデルを 用いて, 照明下の表示デバイスの最大輝度を推定した場合, 物理的には輝度が高く計測されるのに対して, 推定された 輝度は周囲の輝度への順応の関係で低く推定される. しか し, 表示された物体の光沢感も, 照明下では相対的に低く 感じることから, 暗室下で作成された光沢感モデルに，こ の順応の関係で低く推定された輝度を入力することにより， 照明下における光沢感の低下を防ぐ画像合成ができると期 待される. 本論文では, この順応の関係で低く推定された 輝度を見かけ上の輝度と定義する，そこで，本節では，暗 室下で作成された両モデルを用いて，様々な輝度を持つ表 示デバイスを様々な照明下で実験を行った。

実験では 2 台の表示デバイスに，それぞれ基準となる画 像と，比較対象となる画像の二つを提示する．基準となる 画像を提示するデバイスは，G社製 C R T ディスプレイ $\left(67.94 \mathrm{~cd} / \mathrm{m}^{2}\right)$ である. 様々な環境での有効性を評価するた め, 光源の種類を表 2 に示す暗室下, 色温度 $3130 \mathrm{~K}$ - 照度 $1140 l x$ の光源下, 色温度 $6550 K \cdot$ 照度 $1800 l x$ の光源下の 3 通り，比較対象となる画像を提示するデバイスの種類を 表 3 に示す 3 通り変化させた計 9 通りの環境で行った.

比較対象となる画像には, 適切に推定された見かけ上 の輝度に合わせて補正した画像と, その輝度に対して $-40 \%,-30 \%,-20 \%,-10 \%,+10 \%,+20 \%,+30 \%,+40 \%$ の誤 差を加えた輝度に合わせて補正した計 9 通りの画像を用い た，基準となる画像は実験を通して一定である.

六人の被験者は基準画像と比較対象画像の二つの画像の 光沢感の差異を評価する. 本モデルが適切に見かけ上の輝 度を推定できていれば，適切に推定された輝度に合わせて 補正した画像の主観評価值が最も高くなると考えられる.
表 3 有効性評価実験で使用したデバイスの種類 Devices used in the experiment.

\begin{tabular}{c|c}
\hline \hline デバイスの種類 & 輝度 \\
\hline D社 L C D & $87.56 \mathrm{~cd} / \mathrm{m}^{2}$ \\
\hline $\mathrm{E}$ 社 C R T & $36.21 \mathrm{~cd} / \mathrm{m}^{2}$ \\
\hline F社 C R T & $18.06 \mathrm{~cd} / \mathrm{m}^{2}$ \\
\hline
\end{tabular}

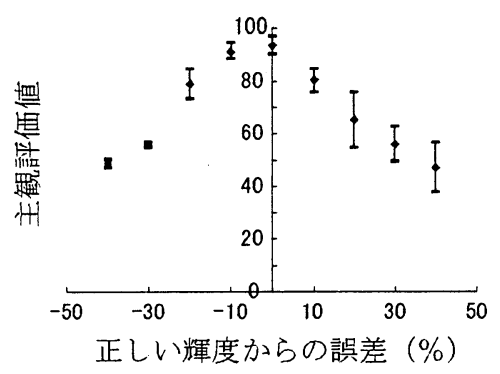

図 9 暗室下での有効性評価実䮠結果 Experimental results in the dark room

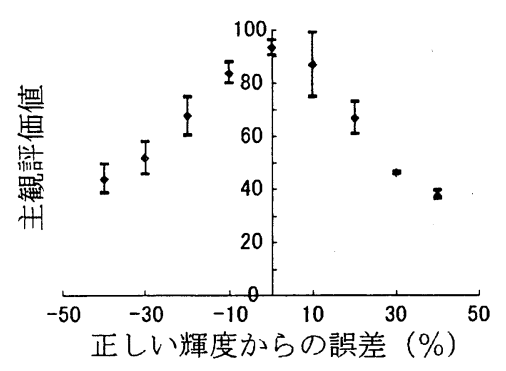

図 10 光源 1 での有効性評価実験結果 Experimental results under the light source \#1.

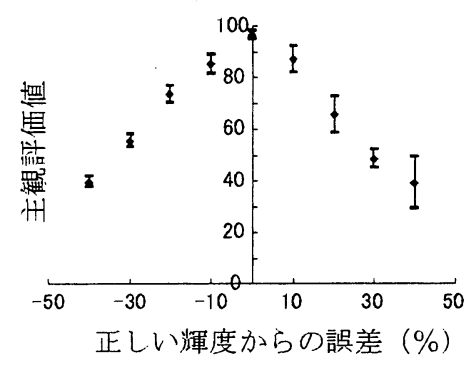

図 11 光源 2 での有効性評価実騃結果

Experimental results under the light source \#2.

図 9,10,11に実験結果を示す，各図において，横軸が画 像合成時に用いた輝度の推定された見かけ上の輝度からの 誤差の割合を表しており, 縦軸が主観評価実験により得ら れた基準画像の光沢感との一致度を表している. 実験結果 は，誤差を加えていない $0 \%$ の時の画像の評価值が最も高 く，本モデルの有効性を確認できた，モデル式は暗室下で 作成したため, 図 9 の標準偏差が最も小さくなっているが, 図 10,11 から異なる光源下でも本モデルが有効であると確 認できた.

\section{6. 商品画像配信システムの構築}

本研究で提案した二つのモデル式を用いて, 簡単な商品 画像配信システムのプロトタイプを構築した。 システムは 顧客が使用している P C などのユーザ側と, 企業が運営し 


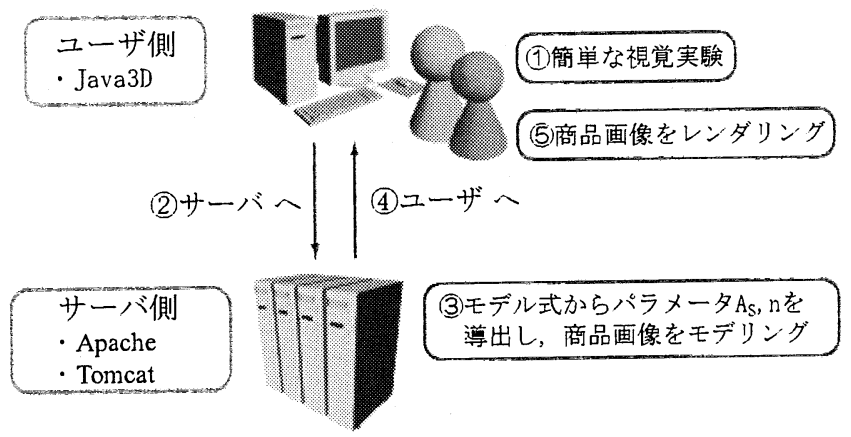

図 12 商品画像配信システム

Prototype system for the online shopping system.

ているサーバ側から構成される．システムの概念図を図 12 に示す。

まずユーザ側で見かけ上の輝度を推定するための簡単な 視覚実験を行う。この視覚実験は，本研究で提案した輝度 推定モデルに基づくものである．視覚実験の情報はサーバ 側に送られ，光沢感補正モデルを用いて表面反射成分のパ ラメータ $A_{s}, n$ を導出する. サーバー側では, 導出された パラメータに基づきコンピュータグラフィックスによる商 品画像のモデリングを行い，ユーザ側に配信する．ユーザ 側ではモデリングデータを用いて商品画像のレンダリング を行うことにより，インタラクティブに任意の質感・視点・ 照明環境での商品画像を閲覧することが可能である.

従来の商品画像配信システムでは，すべてのユーザに対 して，サーバ側に予め準備されている商品画像を配信する ため，表示デバイス間の差異が問題となっていた．本シス テムでは各ユーザの視覚実験情報に基づき，各ユーザに対 して商品画像をモデリングすることが特徵であり，ユーザ の使用している表示デバイスに適した画像を提供すること が可能である.

\section{7. まと め}

本研究では，デバイスに依存しない光沢感再現を目的と して，光沢感補正モデルと輝度推定モデルの二つのモデル 式を提案した．人間の心理的特性である光沢感と，物理的 特性である物体の表面反射成分のパラメータ・表示デバイ スの輝度の関係を定量化し, 表示デバイスの輝度に応じて 最適なパラメータを導出することで, 表示デバイスの輝度 に依存しない光沢感補正モデルを提案した。

また，人間の視覚による実験結果と表示デバイスの輝度 の関係を定量化し，放射輝度計などの特別な測定装置を必 要とせず，高速に表示デバイスの輝度を取得することがで きるモデルを提案した。

さらに，光沢感補正モデルと輝度推定モデルを組合せ，簡 単な視覚実験から顧客の使用しているデバイス，照明環境 下における光沢感再現を実現した，このとき，輝度推定モ デルより得られる輝度は, 照明下の表示デバイスに対する
見かけ上の輝度であり，この見かけ上の輝度を介して光沢 感補正モデルにより光沢感を制御した。 また，表示デバイ スに依存しない, 光沢感再現が可能となるインタラクティ ブな商品画像配信システムを構築した.

本研究で行った主観評価実験は, 物体の表面反射成分と 人間の心理量である光沢感を定量化する目的で行ったため, 物体の内部反射成分や形状は一定としていた。 しかし今後 の課題としては，物体の色や形状などのより多くのパラメー 夕を考慮した光沢感補正モデルの構築が挙げられる.また， 本研究では，表示デバイスのガンマ特性は一定としている. しかし，ガンマ特性が保持されている場合は，輝度推定実 験において知覚できる限界の背景と輝度差と, 最大輝度に は高い相関があるが，ガンマ特性が変化した場合にはこれ は保障されない，今後，ガンマ特性を考慮した輝度推定手 法の開発 ${ }^{11}$ が必要である.

\section{〔文献〕}

1) James A. Ferwerda et al. : "A psychophysically based model of surface gloss perception.", SPIE Human Vision and Electronic Imaging IV, pp.291-301 (2001).

2) B. Phong. : "Illumination for computer-generated pictures.", Communications of the ACM, 18, 6, pp.311-317 (1982).

3) S. A. Shafer. : "Using color to separate reflection components.", COLOR Research and application, 10, 4, pp.210-218 (1985).

4) Michael Oren and Shree K. Nayer. :"Generalization of the Lambertian Model and Implications for Machine Vision.", International Journal of Computer Vision, 14, pp.227-251 (1995).

5) K. E. Torrance and E. M. Sparrow. : "Theory for Off-Specular Reflection From Roughened Surfaces.", J. Opt. Soc. Am, 57, 9 pp.1105-1114 (1967).

6) Cook R. L. and K. E. Torrance. : "A reflectance model for computer graphics.", Computer Graphics, 15, 3 pp.307-316. (1982).

7) Ward G. J. : "Measuring and modeling anisotropic reflection.", Computer Graphics, 26, pp.265-272 (1992).

8) IEC 61966-2-1,"Multimedia Systems and Equipment -Colour Measurement and Management- " Part 2-1 : Colour Management - Default RGB Colour Space sRGB, IEC. (1999).

9) ICC. Spec ICC.1 1998-09, File Format for Color Profiles. ICC. (1998).

10) Mason Woo et al. : "OpenGL Programming Guide.", Addison-Wesley Developers Press (1997).

11) Raja Balasubramanian, Karen M. Braun, et al: "Color Doucments in the Internet Era.", The Industrial Physicist JUNE/JULY 2001 pp.16-20 (2001).

12) K. Tonsho, Y. Akao, N. Tsumura, Y. Miyake. : "Development of goniophotometric imaging system for recording reflectance spectra of 3D objects.", Proceeding of SPIE, 4663, pp.370-378 (2001).

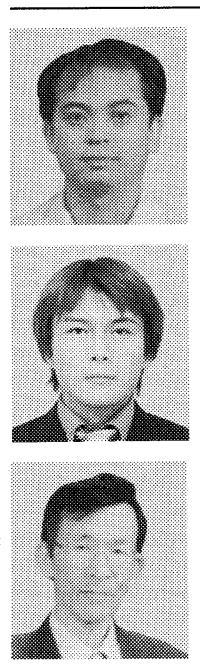

津村 徳道 1995 年大阪大学大学院博士後期課程 修了. 現在, 千葉大学工学部情報画像工学科助教授, 医 用画像工学, 計測画像工学, 色再現工学, 質感再現工学 の研究に従事. 博士 (工学)

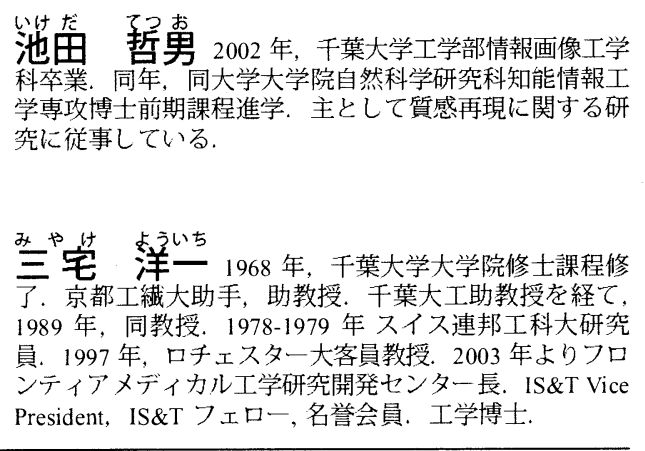

